\title{
Medicine and Economy in an Ever-Changing World
}

\author{
Jörg Melzer ${ }^{a, c}$ Sascha Melzer ${ }^{b}$ Reinhard Saller ${ }^{c}$ \\ ${ }^{a}$ Clinic for Psychosomatic Medicine and Psychotherapy, University Medicine Göttingen, Georg-August University, Göttingen, Germany; \\ ${ }^{b}$ Medical Practice for Psychotherapy, Göttingen, Germany; \\ ${ }^{c}$ University of Zurich, Zurich, Switzerland
}

With this editorial, we invite you to follow our considerations on values in medicine. When the rock band 'U2' released the Hollywood remix of their song 'Desire', the lyrics were about voodoo economics - referring to a kind of trance-like (mass) behavior based on group expectation to make money - and the beat expressed the aggressive and accelerating mode of it [1]. Well, this is the privilege of art: speaking about the dark side of human behavior while offering the pleasure of music. In contrast, the reflection of human behavior in science is usually more theoretical and might elicit intellectual pleasure. However, values are freely praised in songs, but does a value-free science exist $[2,3]$ ?

Values in medicine, as in any other discipline, are shaped by our actions. In former times, we were used to misuse in medicine being more predictable. Let us reflect some examples which attracted attention: scientists, generally known for advancing their discipline or patient care by new research methods, became noted for receiving money from an industry that in return demanded far too positive study outcomes (e.g., A.R. Feinstein and his alliance with the tobacco industry [4]). Or publishing houses, famous for issuing latest results to foster mankind, but one of them, for example, once got mixed up in arms trades with cluster bombs (e.g., Elsevier [5, 6]). How is it today? Misuse like this is not our main problem even though all this can still happen despite efforts to prevent the worst by publishing disclosure statements $[7,8]$. However, misuse of the above-mentioned kind might be seen as peanuts compared to what is going on today and might come tomorrow. Are we aware of the impact of new conflicting developments in medicine?

After rapid developments in medicine in the last decades, we are confronted with complex changes at high speed. To give some examples, we see the change from social to neoliberal economy with privatization of clinics, implementation of diagnosis-related groups (DRGs) and promotion of digitalization/digitality [9-12]. All this obviously exceeds our imaginations of predictable ways of use and misuse. In some countries, Germany for instance, it took a long time until the negative effects of the privatization of clinics were realized [13], e.g.: the process of market making in medicine [14,
15] with a far-reaching change in the physician-patient relation, rendering patients lump sum cases [16]. Even an increased patient mortality was found due to this development [17]. Additionally, a change in medical students' behavior toward patients was noticed due to a shift toward market norms [18]. Moreover, a decline in US students' empathy during medical school was found to be affected by resource allocation, emphasis on technology, and lack of positive social role models [19]. Only now, after about 20 years, medical associations proclaimed 'medicine before economy' as a codex for the physician-patient relationship $[20,21]$ and received support from the German Ethics Council [16]. Meanwhile, the number of hospitals having been privatized has doubled up to more than $30 \%$. Ironically, some aspects of the dreaded cost explosion in healthcare, which had to serve as a justification for privatization, might turn out to be quite different than assumed [22, 23]. Of course, economic feasibility is crucial for good healthcare. But a mere profit-and-loss orientation is inappropriate to ensure a patientcentered medical treatment.

The increased economic pressure on hospitals and doctors' offices affects the number of personnel and the time available in diagnostic or therapeutic encounter. One could get a notion that meanwhile we tend to produce our future patients, as stress has been recognized to contribute to the development of chronic diseases. The circle seems to be closed $[24,25]$.

Recently, digitalization and digitality are about to change education at schools and universities (e.g., education 4.0 [26]) and patient-physician relationships in the medical field (e.g., big data analyzing) [27]). And again, we are calmed by the majority of politicians and health economists - and probably we calm ourselves that these changes would allow for an affordable health system or an 'ever-flourishing health economy' [28]. While the technical side of digitalization brings innovation for data storage or data transmission, the protagonists of a 'New Digital World' [29] foster ideas about digitality that have a far-reaching impact on social human life. The term 'social media' seems almost unrelated to historical developments, as if books, newspapers, telephones, or television

\section{KARGER}

(c) 2018 S. Karger GmbH, Freiburg

Fax +497614520714 
had not been social media as well. It might be better to speak of web-based social media or simply new social media instead. Well, the new social media (e.g., Instagram, Twitter, Facebook) and instant-messaging services (e.g., Skype, WhatsApp), in combination with smartphones and tablets, realized an old human dream being able to get in contact more autonomously. We are now able to digitally stay in touch, quickly and seemingly independently. That often leads to emotional disclosure and can create affective phenomena in a collective manner [30]. The former has indeed been found to be the key feature of intimacy for students using new social media and communicating publicly in a large network, and an estimated large audience led somehow to higher levels of life satisfaction and perceived support [31].

Yet, the reverse of this narcissistic feed, which pertains to the almost ubiquitous availability of new social media, is discussed as well. Unprofessional behavior has been found to be prevalent among surgical residents who used Facebook. The authors concluded: the fact that $14.1 \%$ of residents' Facebook accounts had potentially unprofessional and $12.2 \%$ clearly unprofessional content (e.g., binge drinking, sexually suggestive photos) bears a risk for the reputation of hospitals and residency programs [32]. Although data like this from small-scale surveys might mostly be unrepresentative - compared to about 1 billion Facebook accounts -, they show not only conflicts of interest and disadvantages while using new social media but also a change in communication values.

Other problems for the physician-patient relationship derive from the digitally quite normal but unprofessional function to connect as friends. While $44 \%$ of patients estimated establishing a friendship with their dentists as not appropriate, an equal proportion of $44 \%$ was happy to establish one via social media [33]. In psychiatry, psychosomatics, and psychotherapy, the problems as to the loss of the therapeutic neutrality occurring from the use of smartphones and web-based social media are immense. Therapistor patient-targeted googling might lead to information never directly received from each other and cause confusion - at best. Furthermore, unwilling violation of boundaries can come from (i) digital technologies within devices like smartphones and (ii) ignorance toward data security and data sovereignty by new social media [34]: the smartphone carried into the therapy sessions in combination with an algorithm for GPS tracking might be used for profiling. One day, you might receive a recommendation to be friends with your patient, as both smartphones have been tracked to 'meet' once a week [35]. So far, there are no constitutional laws to prevent this from happening.

Caution seems rare. Studies are undertaken to show an additional positive effect for patients of being friends with their psychiatrist on Facebook and of using this platform at least $1 \mathrm{~h}$ (!) per day, while taking an antidepressant - compared to taking an antidepressant alone [36]. Yet, the question 'whom do the mixing of private and professional life and using web-based technologies serve' is not asked. Professionalism takes time, money, and human beings who take responsibility. Do we really want cheaper digital solutions because business economics tell us that nowadays personal, human, face-to-face contacts be too expensive?
Yet, another problem seems to be that web-based social media mistake information sharing for creation of information for communication. This led to the deactivation of Google Wave, for instance. Communication, according to Sennett, 'is much about what is left unsaid as said; communication mines the realm of suggestion and connotation. ... The divide between information and communication affects the institutional practice of cooperation' [37].

There was a time when risk assessment in medicine was taken seriously. As far as digitality in medicine is concerned, we only know some limited short-term effects. Nonetheless, sometimes we may hear people talk about 'digital natives' as if this was a special, favorable kind of man. We must not forget that the term digital native only refers to handiness for technical applications around the World Wide Web. Technical skills do not make a person a native in human, cultural, constitutional, or ethical values. How did webbased social media and digitality become integral to the construct and identity of the current generation of youth?

Bit by bit, we seem to sacrifice our human values because we believe in business economics which tell us that time spent for human affairs, education, development was not affordable any more. And it is true: to foster humanness we need understanding, negotiation, cooperation, shared intentions, relatedness, reciprocity, and all this takes efforts and time. Time sometimes is money, and all this would be reasonable in terms of sustainability in political economics. But can human values in Western societies, which have been developed over centuries, like respect, dignity, responsibility, democracy, be expressed in the language of business economics - profit making?

All the confusion potentially evolving from digital contact between real human beings does not seem to alter curiosity, megalomania, and economic greed, though. The wide range of research on robotics is a further task. The stimulus to implement robotics (e.g., service robots, companion robots, cognitive-therapy robots) in healthcare settings is clearly seen by protagonists. They propose that the 'sociotechnical challenges' should be proactively addressed, exactly to replace individual aspects of 'human performance' in the so-called Fourth Industrial Revolution. However, robotics will change social settings. We have to decide to what extent we allow our society to change due to the premise of saving personnel costs, e.g., for nursing [38]. From some of these robotic solutions, it is only a short way to what some authors signify as a whole new world 'in which knowledge evolves from a cultural heritage into a commodity' [39]. We seem to be well advised to take an accurate view, as some authors want this 'New Digital World' [40]: they praise 'artificial humans', so-called 'Embodied Conversational Agents' [40], to facilitate human-technology interaction by improving interpersonal communication and social-information processing with artificial intelligence. For that, they take into account the emotional and relational aspects of communication with an emphasis on non-verbal behavior. That means, robots ought to be equipped with socio-emotional intelligence to be able to respond to social affordances. 'The creation of credible artificial humans' is thought for testing 'the understanding of human communication and social cognition' as well as 'the underlying psychological pro- 
cesses and neural mechanisms' [40]. This seems to pave the way to exchanging humans by robots.

Psychotherapeutically spoken, the narcissistic value of the focus on digitality as well as (private) robot solutions becomes clearer when we break it down to wishes and phantasies like participating in something great (latest digital development), being independent of (fallible) humans, satisfying expectations immediately (online shopping), utilizing others (robot companion), fostering one's lack of empathy (superficial 'likes'). All these narcissistic items contribute to an absence of relatedness and flatness of sensation in interpersonal life. This once led to the rise of the authoritarian personality [41] and can be allocated to today's socialization of people under antidemocratic developments in neoliberal societies [42, 43].

In contrast to this possible misuse, the course of developmental psychology showed sustainable ways to treat human beings in a related way. The attachment theory according to Bowlby [44] has taught physicians and psychotherapists that an individual's ability to become emotionally and physically attached to another person is linked to a stable and secure parental object (person). The anthropogenic need for psycho-social development is fulfilled through face-to-face interaction between human beings.

We are just about to realize that early child care in nurseries, outside of stable parental-object relations, can have a negative impact on children. Thus, early separation in the period of attachment constitutes a risk for developing an insecure attachment style which leads to interactional and social problems in youth as well as adulthood [45]. Consequently, we have to face that early child care serves a profit-oriented business economy as it brings mothers quicker back to work. It has been found that the attachment style of people who have been neglected in childhood is insecure, but can be improved by psychotherapy later on [46, 47]. Interestingly, one study showed 'that pathological Internet use was seen as a function of insecure attachment and limited interpersonal relationship' [48].

Quiet and safe spaces for children, families, and friends to develop real social relations are getting rarer. The neoliberal 'need' to be flexible erodes formerly common leisure zones like evenings and weekends. The exhausted individuals seek for help and find it in superficial distraction: television and smartphones for children, 'The Sims' for the youth, series for adults, and maybe robot companions for the elderly in the future. Face-to-face interaction and relatedness disturbs the willingness to participate in lifestyle and workflow of neoliberal socialized beings.

What do all the above-mentioned aspects have to do with this journal? Considered superficially, it would be simply the fact that COMPLEMENTARY MEDICINE RESEARCH used to have a Facebook account which we decided to shut down at the editorial board meeting last summer. We no longer wanted to be active in a new social network that does not care much about social values like respect, dignity, direct communication, reciprocity, human relatedness and basic human rights (e.g., privacy, egality).
However, beyond this small action of ours, the development of e-health and e-communication touches one of the principles of complementary and alternative medicine (CAM) - the doctor-patient communication. Surveys showed that patients favor time and relatedness in the physician-therapist interaction in CAM counselling $[49,50]$. Yet, this is not only relevant for CAM but also for psychosomatic or psychotherapeutic medicine as well as primary care, to mention but a few. Now, when economy tries to convince consumers that indirect communication via electronic devices is better than the real thing, we have to ask: for whom? For business volumes, these developments are beneficial in the short run (e.g., sales of technical devices and updates). In the long term, however, the total opposite is the case with regard to sustainability (e.g., reduction of staff due to technical solutions for whom finally states/ citizens have to pay social welfare; overconsumption of resources in one area and living at the expense of people elsewhere).

We have to acknowledge that digitalization is a good thing for storage and fast transmission of data. One characteristic of digitality is that algorithms - created by technicians - canalize information. That helps to reduce the complexities of our societies, which are already overloaded with information. But that creates new (meta-)information that surely influence our actions. This leads to a kind of digital communality and digital self-referential meaning [51]. As this opens a space for a feeling of participation, but someone else controls the algorithm, the question is: participation in what? At best, a kind of meta-communication, which obviously addresses certain aspects of common ground, is possible. Yet, the door is truly open for manipulation here: reduction of complexity can lead to a presetting of information and thus stirred interactions [52].

We have to decide whether we want technical interactions, stamped by algorithms, realized by fast digital solutions, easy to manipulate due to authoritarian decisions. Or do we want emotionally related interactions, stamped by direct human affections, realized by slower negotiations, and not so easy to manipulate? The choice is ours.

\section{Disclosure Statement}

We have no actual or potential conflict of interest in relation to this editorial. However, we write as professionals in internal medicine, psychiatry, psychotherapy, psychosomatics, and CAM. Our viewpoint might not necessarily be that of the editorial board.

\section{References}

To access the references, please refer to $w w w \cdot$ karger.com/?DOI=492482. 